\title{
Shift work and sleep: medical implications and management
}

\begin{abstract}
The primary occupation of a worker can play an important role in achieving good sleep, as well as good physical and mental health. Shift Work Sleep Disorder (SWSD) is a condition that results from working atypical shifts (i.e. other than the typical $9 \mathrm{am}$ to $5 \mathrm{pm}$ schedule). Individuals who manifest SWSD usually complaint of trouble sleeping, excessive sleepiness and fatigue which interfere with overall functioning. Misalignment of circadian timing system results in undesirable health consequences. Among shift workers, good sleep is essential for efficient functioning. Disturbed sleep is associated with anxiety, depression, poor physical and mental health and eventually, leads to impaired quality of life. The economic burden of undiagnosed, under-and untreated shift work is high. The healthcare workers and policymakers can play a pivotal role in dealing with this issue by educating the public and providing them with adequate privileges to perform their work.
\end{abstract}

Keywords: circadian rhythm, comorbidities, sleep, shift work, stress
Volume I Issue 2- 2017

\author{
Shazia Jehan,' Ferdinand Zizi,' Pandi-Perumal \\ $\mathrm{SR},{ }^{2} \mathrm{~K}$ Myers A, ${ }^{3}$ Evan Auguste, ${ }^{4}$ Jean Louis \\ G,' Samy I McFarlane ${ }^{4}$ \\ 'Department of Population Health, Center for Healthful \\ Behavior Change, USA \\ ${ }^{2}$ Fordham University, USA \\ ${ }^{2}$ Somnogen Canada Inc, Canada \\ ${ }^{3}$ Department of Medicine, SUNY Downstate Medical Center, \\ USA
}

Correspondence: Samy I McFarlane, Distinguished Teaching Professor of Medicine and Endocrinology, State University of New York-Downstate Medical Center, Brooklyn District President, American College of Physicians, 450 Clarkson Avenue, Box 50, Brooklyn, New York, I I 203, USA, Tel 7I8-270-37II, Fax 7I8-270-6358,

Email smcfarlane@downstate.edu

Received: August 04, 2017 | Published: October 06, 2017
Abbrevations: SWSD, shift work sleep disorder; PTSD, post-traumatic stress disorders; QOL, quality of life; CVD, cardiovascular diseases; CRP, c reactive protein; $\mathrm{CSCR}$, central serous chorioretionopathy; LBP, lower back pain; NIOSH, the national institute for occupational safety and health; T2DM, type 2 diabetes mellitus; MetS, metabolic syndrome

\section{Introduction}

A shift worker can work overnight, early mornings or alternate between shifts. These disruptions, especially night work, can have consequences for the sleep and wake states, also known as circadian rhythm. When individual works outside of the typical 9 am to $5 \mathrm{pm}$ hours it is called shift work. This schedule could mean working during nights or early mornings. ${ }^{1}$ Circadian rhythm, which is mediated by a suprachiasmatic nucleus in the hypothalamus, is essential for the normal good health of a person. This circadian rhythm is disrupted in a nightshift worker and can compromise a person's health. ${ }^{2}$ Shift workers have a higher prevalence of insomnia and mental disorders compared to non-shift workers. ${ }^{3}$ Sleep disturbance occurs in shift workers because of the disturbance of circadian rhythm. Circadian rhythm disturbance causes hormonal disturbance of several hormones, including melatonin and cortisol, thus leading to an increased risk of metabolic syndrome (MetS) disorders such as obesity and type 2 diabetes mellitus (T2DM). Shift workers have increased white blood cell counts compared to non-shift workers, which can lower immunity. In addition, to causing problems on a molecular or hormonal level, shift work can impede a person's daily functioning. ${ }^{4}$ The poor sleep that results from disruption of circadian rhythms can lead to cognitive impairment and work under-performance; this can be overcome with good social support and a supportive work environment. ${ }^{5}$ Preventive measures to reduce psychosocial stress at work places such as family support, social support and better work environment can decrease sleep problems and a worker can then be more efficient and productive during working hours. ${ }^{6}$

\section{Gender difference and shift work}

To increase productivity at work, a minimally stressful work environment is necessary. To cope with job stress, temper control, intervention with controlling depressive mood symptoms, and good sleep quality of an employee, especially among female nurses, could lead to a better and more productive work environment. ${ }^{7}$ Like nurses, female physicians are also at risk for increased job stress. The increased workload could cause female doctors to suffer from severe mental health problems, like depression and sleep disturbance, thus affecting their professional and personal lives. ${ }^{8}$ Female executive workers are another group of professionals at higher risk of sleep disturbance due to the high demand of their executive work as compared to non-executive workers. The rigorous job demands can be offset by strong family and social support. ${ }^{9}$ Women employees show more post-traumatic stress disorders (PTSD) compared to male employees in military occupations. ${ }^{10}$ Overall, shift work in female workers can lead to problems in woman's personal and professional lives, due to the atypical hours and increased physical exertion at work. ${ }^{11} \mathrm{~A}$ consequence of this is that women night shift workers have a higher risk of stroke compared to non-shift workers. ${ }^{12}$ 


\section{Occupational stress and sleep disturbance}

The relationship between poor sleep and stress is bi-directional People can develop sleep problems if their working environment is highly stressful; and workplace stress can also contribute to anxiety and depression disorders which are both associated with disturbed sleep..$^{13}$ A stressful environment at work and shift work both can cause disturbed sleep. ${ }^{14}$ Less psychosocial support and highly demanding jobs can be a causative factor of stress and sleep disturbance, compared to good psychosocial support and better work environment. ${ }^{15}$ Stress in the workplace because of high-demand jobs and lack of psychosocial support can also cause disturbed sleep. ${ }^{16}$ Stress in the workplace is one of the major risk factors of insomnia, along with lack of social support and an uncomfortable work environment. ${ }^{17}$ Stressful situations can cause disturbed sleep, and people who experience sleep disturbance due to situational stress can develop insomnia in the future. ${ }^{18,19}$ An occupational change from a less straining job to a higher straining job can significantly increase sleep problems. ${ }^{20}$ People with disturbed sleep cannot perform their daily activities efficiently. They also tend to show a more depressed mood and have low energy during the daytime. ${ }^{21}$ Disturbed sleep impairs quality of life (QOL) and daytime functioning. ${ }^{22}$ Disturbed sleep is also responsible for workplace hazards and errors. Because of insomnia, workplace hazards and errors end up costing employers hours and days of work. Workplace accidents due to insomnia-related issues lead to costs greater than any chronic disease. ${ }^{23}$ Work performance is poor in people suffering from insomnia and lead to high costs because of decreased performance at work as working with disturbed sleep can cause less efficient work. ${ }^{24}$ Job strain increases sleep disturbance when rewards at work are not given and over commitment is required. ${ }^{25}$ The nature of the occupation, strenuous physical exertion, and continuous mental stress in the workplace can disturb sleep or may increase sleep problems in the insomniac population. Disturbed sleep can cause poor work performance as well as absenteeism from work, which is also a significant economic burden. Accidents and errors in the workplace due to disturbed sleep have a severe negative impact on the economy. ${ }^{26}$ People with insomnia have poorer work performance and their healthcare cost is higher compared to people with the good quality of sleep. ${ }^{27} \mathrm{SWSD}$ is also common in flying crews, where more alertness and cognitive functions are required. So the cooperation of colleagues, proper scheduling of shift work, and teamwork are very necessary working in the international space station. In flying, the hectic schedule of shift work leads to more SWSD compared to other professions.$^{28}$ Sleep quality is poorer among nurses who do shift work compared to nurses who never did shift work. ${ }^{29}$ Even nightshift police officers have poorer sleep quality compared to day workers. ${ }^{30}$

\section{Prevalence of insomnia worldwide}

Insomnia is a rapidly growing global health issue. Disturbed sleep affects all aspects of an individual's daily life functioning. People are frequently involved in traffic accidents and have claimed that hazards have been created in the workplace due to insomnia.

As shown in Table 1, a study a national survey conducted examining Australian sleep habits reveals the prevalence of insomnia to be $33-45 \% .^{31}$ This is not much different from the results seen in the Netherlands in which the prevalence of insomnia is $32.1 \% .^{32}$ As seen in American studies, Insomnia greatly affects an individual's health and is also a significant cause of depression..$^{33}$ Insomnia rates are higher in the elderly population, and the condition is associated with a decline in cognitive functioning, a decline in daily physical functioning, and a poor quality of life. ${ }^{34}$ Other increasing medical and psychosocial health issues are the underlying factors of insomnia, all of which compromise the physical and mental health of an individual. ${ }^{35}$ Another study also confirms that the prevalence of insomnia is more common among the elderly, as well as people with psychosocial stress. ${ }^{36}$ To reduce anxiety and depression due to insomnia, people are taking sleeping medications such as benzodiazepine, for example. But healthcare workers should be concerned about the excessive use of benzodiazepines and their negative side effects. ${ }^{37}$

Table I The prevalence of insomnia worldwide

\begin{tabular}{|c|c|c|c|c|}
\hline Study title & Study design & $\mathbf{N}$ & $\begin{array}{l}\text { Prevalence } \\
\text { of insomnia }\end{array}$ & References \\
\hline $\begin{array}{l}\text { Sleep health of Australian adults in 2016: results of the } 2016 \text { Sleep Health } \\
\text { Foundation national survey }\end{array}$ & Cross-sectional & 1011 & $33-45 \%$ & 31 \\
\hline Epidemiology of sleep and sleep disorders in The Netherlands & Epidemiological study & 2089 & $32.10 \%$ & 32 \\
\hline $\begin{array}{l}\text { Quality of life, sleepiness and depressive symptoms in adolescents with insomnia: } \\
\text { A cross-sectional study }\end{array}$ & Cross sectional study & 6919 & $8.30 \%$ & 33 \\
\hline $\begin{array}{l}\text { Cognitive and affective functions associated with insomnia: a population-based } \\
\text { study }\end{array}$ & Population based study & 142 & $36.20 \%$ & 34 \\
\hline $\begin{array}{l}\text { The Prevalence of Insomnia, Its Sociodemographic and Clinical Correlates, and } \\
\text { Treatment in Rural and Urban Regions of Beijing, China: A General Population- } \\
\text { Based Survey }\end{array}$ & $\begin{array}{l}\text { Logistic regression } \\
\text { analysis }\end{array}$ & 5,926 & $9.20 \%$ & 35 \\
\hline An epidemiological study of insomnia among the Japanese general population & $\begin{array}{l}\text { Multiple logistic } \\
\text { regression analysis }\end{array}$ & 3030 & $21.40 \%$ & 36 \\
\hline Epidemiological study on insomnia in the general population & Epidemiological study & 5,622 & $20.10 \%$ & 37 \\
\hline
\end{tabular}




\section{Shift work and associated comorbidities}

Shift work is associated with disturbed circadian rhythm, which is involved in the torrent of disturbed physiological and pathological mechanisms. This disruption is not only a risk factor for breast cancer, but can also be a risk factor for T2DM, obesity, hypertension, MetS, Cardio Vascular Diseases(CVD), stroke, acute respiratory infections, gastrointestinal tract problems (GIT), menstrual problems, back pain, headaches, anxiety, mood disorders and depression. ${ }^{38-44}$ Night shift workers are at a higher risk of hypertension. ${ }^{45,46}$ Inflammatory markers such as C Reactive Protein (CRP) and leukocyte counts are higher in shift workers and are associated with CVD, atherosclerosis, stroke, andT2DM. ${ }^{47-49}$ Increased leukocyte count is one of the major risk factors for CVD, and ischemic stroke. ${ }^{50}$ Increase leukocyte count is a risk factor and also a prognostic factor for CVD. ${ }^{51}$ Working night shifts is a risk factor for poor diabetes control, as hemoglobin A1c is higher among night shift workers with T2DM compared to working day shifts. ${ }^{52}$ Disturbed sleep, OSA and shift work are risk factors for T2DM and all patients with sleep problems should be screened for T2DM. ${ }^{53}$ Shift work is also associated with a disturbed lipid profile, high triglycerides and low HDL levels are often noticed among shift workers. ${ }^{54}$ High triglycerides, low HDL cholesterol findings among shift workers are associated with MetS compared to non-shift workers. ${ }^{55}$

Shift workers females have higher incidence and prevalence of breast cancer compared to non-shift workers. This is because there is more light exposure at night and the release of melatonin is suppressed, which predisposes women to breast cancer through a series of physiological and pathological mechanisms. ${ }^{56}$ Disruption of the circadian rhythm can disrupt the rhythmicity of different genes in breast tissues, which controls the normal texture of the breast tissues and biology and can lead to breast cancer. ${ }^{57}$ Light exposure at night among shift workers suppresses the normal release of melatonin from the pineal gland and could also stimulate the production of estrogen from the ovaries, which could in turn cause breast cancer. ${ }^{58}$ Working for a prolonged time period in shift workers is a risk factor for a breast cancer due to the disruption of circadian rhythm and decreased the production of melatonin hormone. ${ }^{59}$ Women are more prone to breast cancer if they start shift work from a very early age and work for a prolonged period of time. ${ }^{60}$ Nurses working nightshifts have a higher risk of breast cancer compared to non-shift workers. The disruption of the circadian rhythm plays an important role because of decreased availability of melatonin in artificial light. Nightshift work and industrial chemical exposure, such as metals, pesticides, lead, and hydrocarbons can be a significant risk factor for breast cancer if it occurs at an early age and for a prolonged period of time. ${ }^{61}$ This disruption is not only a risk factor for breast cancer, but can also be a risk factor for, anxiety and mood disorders such as depression. ${ }^{39}$ Depression is mentioned among nightshift workers due to sleep disturbance compared to day shift workers (Figure 1)..$^{62,63}$

Healthcare professionals, such physicians and nurses are at a higher risk for migraines compared to the general population. ${ }^{64}$ The additional stress of on-call schedule scan cause physicians GIT problems due to disturbed sleep and psychological work stress. ${ }^{65}$ Longer working hours, improper sleep, less physical activity, and shift work leads to lower back pain (LBP) among taxi drivers and other employees who spend significant amounts of their workday driving, such as truck drivers, letter carriers, or even police officers. ${ }^{66}$ Shift workers have a cognitive decline and impaired work efficiency compared to non- shift workers. ${ }^{5}$ Disturbed sleep can cause drowsiness, which is a major cause of road traffic accidents. ${ }^{67}$

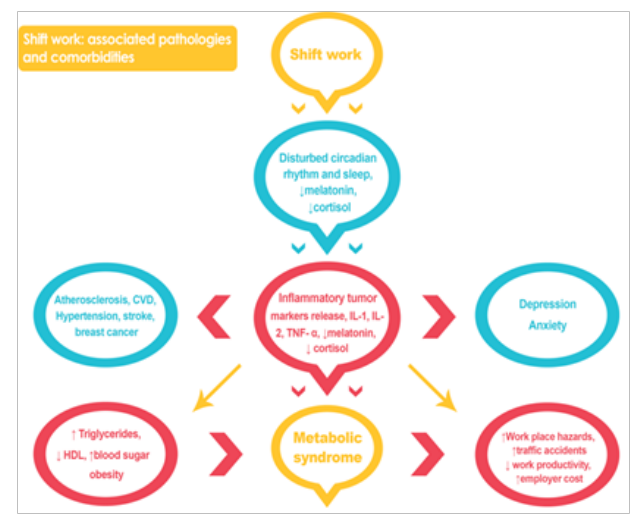

Figure I shift work associated pathologies and comorbidities.

\section{Management of insomnia, better sleep, better functioning, reduce economic burden}

Chronic insomnia is one of the major causes of depression and is associated with a decrease in quality of life (QOL) and poor functioning in the workplace. It should be treated by addressing the underlying causative factors widely or through a referral to a sleep specialist. ${ }^{68}$ Chronic insomnia can be best treated by using non-pharmacological techniques, such as cognitive behavioral the rapies or reviewing sleep hygiene. For the acute symptoms of insomnia, hypnosis can be an effective therapeutic measure. ${ }^{69}$ Sleep disturbance should be addressed as soon as possible to reduce the potential physical and mental health complications. ${ }^{70}$ High-demanding jobs and over-commitment can cause sleep disturbances, and work-related sleep disturbance can be overcome by good family support, giving rewards at the work place, and a strong supportive work environment. This work support can prevent future insomnia-related problems. ${ }^{71}$ Higher job strain leads to disturbed sleep, lower job strain, and good social support can improve sleep problems. ${ }^{72}$ Stress management training and techniques can help cope with sleep disturbance among certain professions such as nursing. These training can last longer and be beneficial for one's future professional career life. ${ }^{73}$ Work stress can lead to disturbed sleep among workers and decreases performance at work. Controlling self-temperament and a cooperative environment among employers, employees, and colleagues can help to decrease sleep disturbance and can increase the work performance and life quality of workers. ${ }^{74}$ Proper sleep hygiene is necessary for good quality sleep; symptoms from insomnia can be reduced with less strain at work. ${ }^{75}$ Switching night work and rotational work can improve sleep disturbances, compared to sticking to the same shift schedule. ${ }^{76}$ Blood pressure control and napping can also play an important role in the management of hypertension-related to shift work. ${ }^{45}$ Hypertension could be reduced among shift workers by scheduling shift work properly and strategies should definitely be taken to overcome sleep disturbance among shift workers. ${ }^{77}$ Shift work is a major risk factor of developing MetS and if shift workers with MetS show a severity of the disease then they should consider a change of work and should be counseled by a health care professional..$^{78,79}$ Health education should be provided to patients about sleep problems and associated co-morbidities related to shift work. Shift work schedules, selection of appropriate people for shift work, and their treatment are key factors in the management of shift worker problems. ${ }^{37}$ A 30 minute nap has been found to effectively 
reduce nurses stress level, thus allowing them to drive home safely at the end of their shift with reduced drowsiness. ${ }^{80}$ Emergency Room physicians who work 24 hours shifts are at increased risk for cardiac strain, which can cause tachycardia. With this in mind, emergency room physicians should reduce their hours as less tachycardia was noted when they worked 14 hours. ${ }^{81}$ Making proper work schedule policies among nightshift-working nurses and their implementation can provide better health care to the patients and also give better sleep quality and healthy working environment to nurses. ${ }^{82}$ The same applies for interns and resident physicians who have to take overnight call. To improve work environment, proper work schedules should be considered allowing for the mandated time off. ${ }^{83}$

Insomnia can be treated pharmacologically; melatonin can help in the facilitation of normalizing the aberrant circadian rhythm. ${ }^{84}$ Benzodiazepine receptor agonist response is good among several insomniac patients and remission rates are very low. ${ }^{85}$ Shift work is associated with several co-morbid conditions and can compromise an individual's physical and psychosocial health. The National Institute for Occupational Safety and Health (NIOSH) guides workers how to cope up with stressful work-related situations and manage their daily healthy physical and mental health. This information and guidelines are easily accessible and their websites are available online for an individual's use and access. These websites and their literature give a thorough guidance regarding the work and health of a worker. ${ }^{86}$

\section{Discussion}

Sleep disturbance due to shift work potentially plays a negative role in workers' health, as it can predispose to chronic diseases such as hypertension, stroke, CVD, T2DM, obesity, decreased immunity, cancer, anxiety, and depression. The underlying mechanism of SWD is a disturbance of the normal circadian rhythm, which leads to the increased release of inflammatory markers; which contribute to obesity, metabolic syndrome or even cancer. ${ }^{87}$ Female shift-workers are at a higher risk of breast cancer compared to non-shift workers because of the disturbance of their circadian rhythm. There is a decreased release of melatonin and cortisol hormones among nighttime shift-workers, which releases a series of inflammatory markers such as IL-1, IL-2, TNF- $\alpha$, thus predisposing a woman to a higher risk of breast cancer. ${ }^{57,88,89}$

Shift workers are at an increased risk for sleep disturbance and increased shift hours can lead to occupational injuries. Due to fatigue and somnolence, shift workers cannot perform their duties efficiently and the productivity outcome of work is also affected. ${ }^{90}$ Sleep disturbance is a major health risk factor among shift workers, and this can be worse if shift hours are of longer duration. ${ }^{91}$ Sleep duration and quality are strongly related to the metabolic functioning of the body, and disturbed sleep slows metabolism, which could lead to weight gain and impaired glucose metabolism..$^{92}$ Insufficient sleep is a major risk factor for T2DM and obesity or it can predispose to both conditions simultaneously. ${ }^{93}$ Female shift workers have the highest incidence of MetS and other health conditions compared to non-shift working women. Shift work is associated with metabolic syndrome, as well as CVD, stroke, breast cancer, and GIT problems. ${ }^{94}$ In the nursing profession, shift work causes sleep disturbance and a lack of physical exercise compromises both physical and mental health. ${ }^{95}$ Commercial motor vehicle drivers are also under the influence of disturbed sleep, due to shift work and long hours, disturbed sleep and a lack of physical exercise are the predisposing factors of the development of obesity, which could also cause MetS. ${ }^{96}$ Shift work is one of the major risk factors of disturbed sleep, which can lead an individual to eat excessively and this could be a factor leading to obesity and disturbance of healthy metabolic functioning of the body. ${ }^{97}$ Night shift work is a major risk factor for sleep disturbance, which is then associated with physical and mental illness. ${ }^{3}$ Shift work with longer duration causes CVD and increased mortality rate. ${ }^{98}$

This global issue of shift work should be addressed by policymakers and healthcare professionals; as shift hours should be suitable without compromising the physical and mental health of shift workers. Reducing shift hours can also be beneficial for a shift worker's health. NIOSH is a good resource for employees and companies on how to manage work stress and shift worker's health. ${ }^{84}$

\section{Conclusion}

Sleep disturbance among shift-workers contributes to the fact that these people are at a greater risk of mental and physical illnesses compared to that of non-shift workers. ${ }^{99}$ Night shift work is associated with poor sleep, and disturbed sleep is a major risk factor for MetS, which is correlated with poor health and can cause poor work performance. ${ }^{100}$ People who work overtime and do not get proper sleep are at increased risk of occupational hazards, and these hazards could be exposures to different chemicals, solvents, fumes, and dust. Working longer hours in this environment can not only disturb people's sleep but also compromise their health. ${ }^{101}$

\section{Acknowledgements}

This work is supported by the following funding agencies: R25-HL105444 and R25-HL 116378 (NHLBI); R01-MD007716 (NIMHD) to GJL. However, the funders had no role in study design, data collection, analysis and decision to publish.

\section{Conflicts of interest}

The authors declared that there are no conflicts of interest.

\section{References}

1. Almeida CM, Malheiro A. Sleep, immunity and shift workers: A review. Sleep Sci. 2016;9(3):164-168.

2. Ball LJ, Palesh O, Kriegsfeld LJ. The Pathophysiologic Role of Disrupted Circadian and Neuroendocrine Rhythms in Breast Carcinogenesis. Endocr Rev. 2016;37(5):450-466.

3. Cheng W, Cheng Y. Night shift and rotating shift in association with sleep problems, burnout and minor mental disorder in male and female employees. Occupational and environmental medicine. 2016;74(2):483488 .

4. Wirth MD, Andrew ME, Burchfiel CM, et al. Association of shiftwork and immune cells among police officers from the Buffalo Cardio-Metabolic Occupational Police Stress study. Chronobiol Int. 2017;34(6):721-731.

5. Cheng P, Tallent G, Bender TJ, et al. Shift work and cognitive flexibility: decomposing task performance. J Biol Rhythms. 2017;32(2):143-153.

6. Johannessen HA, Sterud T. Psychosocial factors at work and sleep problems: a longitudinal study of the general working population in Norway. Int Arch Occup Environ Health. 2017;90(7):597-608. 
7. Kikuchi Y, Nakaya M, Ikeda M, et al. Relationship between job stress, temperament and depressive symptoms in female nurses. Int J Occup Med Environ Health. 2014;27(3):426-434.

8. Győrffy Z, Dweik D, Girasek E. Workload, mental health and burnou indicators among female physicians. Hum Resour Health. 2016;14(1):12.

9. Gadinger MC, Fischer JE, Schneider S, et al. Female executives are particularly prone to the sleep-disturbing effect of isolated high-strain jobs: a cross-sectional study in German-speaking executives. J Sleep Res. 2009;18(2):229-237.

10. MacGregor AJ, Clouser MC, Mayo JA, et al. Gender differences in posttraumatic stress disorder among US Navy healthcare personnel. $J$ Womens Health (Larchmt). 2007;26(4):338-344.

11. Åkerstedt T, Fredlund P, Gillberg M, et al. Work load and work hours in relation to disturbed sleep and fatigue in a large representative sample. Journal of psychosomatic research. 2002;53(1):585-588.

12. Brown DL, Feskanich D, Sánchez BN, et al. Rotating night shift work and the risk of ischemic stroke. Am J Epidemiol. 2009;169(11):1370-1377.

13. Kim BH, Lee HE. The association between working hours and sleep disturbances according to occupation and gender. Chronobiol Int. 2015;32(8):1109-1114.

14. Palmer KT, D'Angelo S, Harris EC, et al. Sleep disturbance and the older worker: findings from the Health and Employment after Fifty study. Scand $J$ Work Environ Health. 2017;43(2):136-145.

15. Portela LF, Kröning Luna C, Rotenberg L, et al. Job strain and selfreported insomnia symptoms among nurses: What about the influence of emotional demands and social support? BioMed Research International. $2015 ; 2015: 820610$.

16. Yoshioka E, Saijo Y, Kita T, et al. Effect of the interaction between employment level and psychosocial work environment on insomnia in male Japanese public service workers. Int J Behav Med. 2013;20(3):355364

17. Kim HC, Kim BK, Min KB, et al. Association between job stress and insomnia in Korean workers. J Occup Health. 2011;53(3):164-174.

18. Jarrin DC, Chen IY, Ivers H, et al. The role of vulnerability in stress $\square$ related insomnia, social support and coping styles on incidence and persistence of insomnia. J Sleep Res. 2014;23(6):681-688.

19. Burgard SA, Ailshire JA. Putting work to bed: stressful experiences on the job and sleep quality. J Health Soc Behav. 2009;50(4):476-492.

20. De Lange AH, Kompier MA, Taris TW, et al. A hard day's night: a longitudinal study on the relationships among job demands and job control, sleep quality and fatigue. J Sleep Res. 2009;18(3):374-383.

21. Espie CA, Kyle SD, Hames P, et al. The daytime impact of DSM-5 insomnia disorder: comparative analysis of insomnia subtypes from the great British sleep survey. J Clin Psychiatry. 2012;73(12):1478-1484.

22. Zammit GK, Weiner J, Damato N, et al. Quality of life in people with insomnia. Sleep. 1999;22(Suppl 2):S379-385.

23. Shahly V, Berglund PA, Coulouvrat C, et al. The associations of insomnia with costly workplace accidents and errors: results from the America Insomnia Survey. Arch Gen Psychiatry. 2012;69(10):1054-1063.

24. Kessler RC, Berglund PA, Coulouvrat C, et al. Insomnia and the performance of US workers: results from the America insomnia survey. Sleep. 2011;34(9):1161-1171.

25. Ota A, Masue T, Yasuda N, et al. Association between psychosocial job characteristics and insomnia: an investigation using two relevant job stress models-the demand-control-support (DCS) model and the effort-reward imbalance (ERI) model. Sleep Medicine. 2005;6(4):353-358.
26. Metlaine A, Leger D, Choudat D. Socioeconomic impact of insomnia in working populations. Ind Health. 2005;43(1):11-19.

27. Hatoum HT, Kong SX, Kania CM, et al. Insomnia, health-related quality of life and healthcare resource consumption. Pharmacoeconomics. 1998;14(6):629-637.

28. Mizuno K, Matsumoto A, Aiba T, et al. Sleep patterns among shift-working flight controllers of the international space station: an observational study on the JAXA Flight Control Team. J Physiol Anthropol. 2016;35(1):19.

29. Zhang L, Sun DM, Li CB, et al. Influencing factors for sleep quality among shift-working nurses: a cross-sectional study in china using 3-factor pittsburgh sleep quality index. Asian Nurs Res (Korean Soc Nurs Sci). 2016;10(4):277-282.

30. Fekedulegn D, Burchfiel CM, Charles LE, et al. Shift work and sleep quality among urban police officers: the bcops study. J Occup Environ Med. 2016;58(3):e66-e71.

31. Adams RJ, Appleton SL, Taylor AW, et al. Sleep health of Australian adults in 2016: results of the 2016 sleep health foundation national survey. Sleep Health. 2017;3(1):35-42

32. Kerkhof GA. Epidemiology of sleep and sleep disorders in The Netherlands. Sleep Med. 2017;30:229-239.

33. Amaral MO, de Almeida Garrido AJ, de Figueiredo Pereira C, et al. Quality of life, sleepiness and depressive symptoms in adolescents with insomnia: a cross-sectional study. Aten Primaria. 2017;49(1):35-41.

34. Hishikawa N, Fukui Y, Sato K, et al. Cognitive and affective functions associated with insomnia: a population-based study. Neurol Res. 2017;39(4):331-336

35. Xiang YT, Ma X, Cai ZJ, et al. The prevalence of insomnia, its sociodemographic and clinical correlates, and treatment in rural and urban regions of Beijing, China: a general population-based survey. Sleep. 2008;31(12):1655-1662.

36. Kim K, Uchiyama M, Okawa M, et al. An epidemiological study of insomnia among the Japanese general population. Sleep. 2000;23(1):4147.

37. Ohayon M. Epidemiological study on insomnia in the general population. Sleep. 1996;19(3 Suppl):S7-15.

38. Anbazhagan S, Ramesh N, Nisha C, et al. Shift work disorder and related health problems among nurses working in a tertiary care hospital, Bangalore, South India. Indian J Occup Environ Med. 2016;20(1):35.

39. Figueiro MG, White RD. Health consequences of shift work and implications for structural design. Journal of J Perinatol. 2013;33(Suppl 1):S17-23.

40. Flo E, Pallesen S, Magerøy N, et al. Shift work disorder in nursesassessment, prevalence and related health problems. PLoS One. 2012;7(4):e33981.

41. Knutsson A. Shift work and coronary heart disease. Scand J Soc Med Suppl. 1988;44:1-36.

42. Sonati J, De Martino M, Vilarta R, et al, Quality of life, health, and sleep of air traffic controllers with different shift systems. Aerosp Med Hum Perform. 2015;86(10):895-900.

43. Sookoian S, Gemma C, Fernández Gianotti T, et al. Effects of rotating shift work on biomarkers of metabolic syndrome and inflammation. J Intern Med. 2007;261(3):285-292.

44. Touitou Y, Reinberg A, Touitou D. Association between light at night, melatonin secretion, sleep deprivation, and the internal clock: Health impacts and mechanisms of circadian disruption. Life Sci. 2017;173:94 106. 
45. Ha M, Park J. Shiftwork and metabolic risk factors of cardiovascular disease. J Occup Health. 2005;47(2):89-95.

46. Rotenberg L, Silva-Costa A, Vasconcellos-Silva PR, et al. Work schedule and self-reported hypertension-the potential beneficial role of on-shift naps for night workers. Chronobiol Int. 2016;33(6):697-705.

47. Morris CJ, Purvis TE, Mistretta J, et al. Circadian misalignment increases c-reactive protein and blood pressure in chronic shift workers. $J$ Biol Rhythms. 2017;32(2):154-164.

48. Puttonen S, Härmä M, Hublin C. Shift work and cardiovascular diseasepathways from circadian stress to morbidity. Scand J Work Environ Health. 2010;36(2):96-108.

49. Puttonen S, Viitasalo K, Härmä M. Effect of shiftwork on systemic markers of inflammation. Chronobiol Int. 2011;28(6):528-535.

50. Lee CD, Folsom AR, Nieto FJ, et al. White blood cell count and incidence of coronary heart disease and ischemic stroke and mortality from cardiovascular disease in African-American and White men and women: atherosclerosis risk in communities study. Am J Epidemiol. 2001;154(8):758-764

51. Madjid M, Awan I, Willerson JT, et al. Leukocyte count and coronary heart disease: implications for risk assessment. $J$ Am Coll Cardiol. 2004;44(10):1945-1956.

52. Manodpitipong A, Saetung S, Nimitphong H, et al. Night $\square$ shift work is associated with poorer glycaemic control in patients with type 2 diabetes. $J$ Sleep Res. 2016;26(6):764-772.

53. Anothaisintawee T, Reutrakul S, Van Cauter E, et al. Sleep disturbances compared to traditional risk factors for diabetes development: systematic review and meta-analysis. Sleep Med Rev. 2016;30:11-24.

54. Karlsson BH, Knutsson AK, Lindahl BO, et al. Metabolic disturbances in male workers with rotating three-shift work. Results of the WOLF study. Int Arch Occup Environ Health. 2003;76(6):424-430.

55. Karlsson B, Knutsson A, Lindahl B. Is there an association between shift work and having a metabolic syndrome? Results from a population based study of 27, 485 people. Occup Environ Med. 2001;58(11):747-752.

56. Leung M, Tranmer J, Hung E, et al. Shift work, chronotype, and melatonin patterns among female hospital employees on day and night shifts. Cancer Epidemiol Biomarkers Prev. 2016;25(5):830-838.

57. Blakeman V, Williams JL, Meng QJ, et al. Circadian clocks and breast cancer. Breast Cancer Res. 2016;18(1):89.

58. Davis S, Mirick DK, Stevens R. Night shift work, light at night, and risk of breast cancer. J Natl Cancer Inst. 2001;93(20):1557-1562.

59. Schernhammer ES, Kroenke CH, Laden F, et al. Night work and risk of breast cancer. Epidemiology. 2006;17(1):108-111.

60. Wegrzyn LR, Tamimi RM, Rosner BA, et al. Rotating night shift work and risk of breast cancer in the nurses health studies. Am J Epidemiol. 2017;86(5):532-540.

61. Fenga C. Occupational exposure and risk of breast cancer. Biomed Rep. 2016;4(3):282-292

62. Kalmbach DA, Pillai V, Cheng P, et al. Shift work disorder, depression, and anxiety in the transition to rotating shifts: the role of sleep reactivity. Sleep Med. 2015;16(12):1532-1538

63. Togo F, Yoshizaki T, Komatsu T. Association between depressive symptoms and morningness-eveningness, sleep duration and rotating shift work in Japanese nurses. Chronobiol Int. 2017;34(3):349-359.
64. Kuo WY, Huang CC, Weng SF, et al. Higher migraine risk in healthcare professionals than in general population: a nationwide population-based cohort study in Taiwan. J Headache Pain. 2015;16:102.

65. Lim SK, Yoo SJ, Koo DL, et al. Stress and sleep quality in doctors working on-call shifts are associated with functional gastrointestinal disorders. World J Gastroenterol. 2017;23(18):3330-3337.

66. Wang M, Yu J, Liu N, et al. Low back pain among taxi drivers: a crosssectional study. Occup Med (Lond). 2017;67(4):290-295.

67. Chen GX, Fang Y, Guo F, et al. The influence of daily sleep patterns of commercial truck drivers on driving performance. Accid Anal Prev. 2016;91:55-63.

68. Doghramji PP. Integrating modern concepts of insomnia and its contemporary treatment into primary care. Postgrad Med. 2014;126(5):82101.

69. Cunnington D, Junge MF, Fernando AT. Insomnia: prevalence, consequences and effective treatment. Med J Aust. 2013;199(8):S36-40.

70. Irish LA, Dougall AL, Delahanty DL, et al. The impact of sleep complaints on physical health and immune outcomes in rescue workers: a one-year prospective study. Psychosom Med. 2013;75(2):196-201.

71. Ota A, Masue T, Yasuda N, et al. Psychosocial job characteristics and insomnia: A prospective cohort study using the Demand-Control-Support (DCS) and Effort-Reward Imbalance (ERI) job stress models. Sleep Med. 2009;10(10):1112-1117.

72. Nomura K, Nakao M, Takeuchi T, et al. Associations of insomnia with job strain, control, and support among male Japanese workers. Sleep Med. 2009;10(6):626-629.

73. Winwood PC, Lushington K. Disentangling the effects of psychological and physical work demands on sleep, recovery and maladaptive chronic stress outcomes within a large sample of Australian nurses. J Adv Nurs. 2006;56(6):679-689.

74. Deguchi Y, Iwasaki S, Ishimoto $\mathrm{H}$, et al. Relationships between temperaments, occupational stress, and insomnia among Japanese workers. PLoS One. 2017;12(4):e0175346.

75. Halonen JI, Lallukka T, Pentti J, et al. Change in job strain as a predictor of change in insomnia symptoms: analyzing observational data as a nonrandomized pseudo-trial. Sleep. 2017;40(1)

76. Thun E, Bjorvatn B, Åkerstedt T, et al. Trajectories of sleepiness and insomnia symptoms in Norwegian nurses with and without night work and rotational work. Chronobiol Int. 2016;3(5):480-489.

77. Lu K, Chen J, Wang L, et al. Association of sleep duration, sleep quality and shift-work schedule in relation to hypertension prevalence in chinese adult males: a cross-sectional survey. Int J Environ Res Public Health. 2017;14(2).

78. Esquirol Y, Bongard V, Mabile L, et al. Shift work and metabolic syndrome: respective impacts of job strain, physical activity, and dietary rhythms. Chronobiol Int. 2009;26(3):544-559.

79. Pietroiusti A, Neri A, Somma G, et al. Incidence of metabolic syndrome among night-shift healthcare workers. Occup Environ Med. 2010;67(1):54 57.

80. Geiger-Brown J, Sagherian K, Zhu S, et al. CE: original research: napping on the night shift: a two-hospital implementation project. Am J Nurs. 2016;116(5):26-33.

81. Dutheil F, Marhar F, Boudet G, et al. Maximal tachycardia and high cardiac strain during night shifts of emergency physicians. Int Arch Occup Environ Health. 2017;90(6):467-480. 
82. Farzianpour F, Nosrati SA, Foroushani AR, et al. Relationship between shift work and personality traits of nurses and their coping strategies. Glob J Health Sci. 2016;8(5):166-174.

83. Surani AA, Surani A, Zahid S, et al. To assess sleep quality among pakistani junior physicians (House Officers): A cross-sectional study. Ann Med Health Sci Res. 2015;5(5):329-333.

84. Reid KJ, Abbott SM. Jet lag and shift work disorder. Sleep Med Clin 2015;10(4):523-535.

85. Pillai V, Roth T, Roehrs T, et al. Effectiveness of benzodiazepine receptor agonists in the treatment of insomnia: An examination of response and remission rates. Sleep. 2016;40(2).

86. Caruso CC. Reducing risks to women linked to shift work, long work hours, and related workplace sleep and fatigue issues. $J$ Womens Health (Larchmt). 2015;24(10):789-794.

87. Herichova I. Changes of physiological functions induced by shift work. Endocr Regul. 2013;47(3):159-170.

88. Ko SB. Night shift work, sleep quality, and obesity. J Lifestyle Med 2013;3(2):110-116.

89. Richter K, Acker J, Kamcev N, et al. Recommendations for the prevention of breast cancer in shift workers. EPMA J. 2011;2(4):351-356.

90. Weaver MD, Patterson PD, Fabio A, et al. An observational study of shift length, crew familiarity, and occupational injury and illness in emergency medical services workers. Occup Environ Med. 2015;72(11):798-804.

91. Lee KH, Ho Chae C, Ouk Kim Y, et al. Anxiety symptoms and occupationa stress among young Korean female manufacturing workers. Ann Occup Environ Med. 2015;27(1):24.
92. Morselli LL, Guyon A, Spiegel K. Sleep and metabolic function. Pflugers Arch. 2012;463(1):139-160.

93. Knutson KL, Spiegel K, Penev P, et al. The metabolic consequences of sleep deprivation. Sleep Med Rev. 2007;11(3):163-178.

94. Lajoie P, Aronson KJ, Day A, et al. A cross-sectional study of shift work, sleep quality and cardiometabolic risk in female hospital employees. BMJ Open. 2015;5(3):e007327.

95. De Martino MM, Abreu AC, Barbosa MF, et al. The relationship between shift work and sleep patterns in nurses. Cien Saude Colet. 2013;18(3):763768 .

96. Lemke MK, Hege A, Perko M, et al. Work patterns, sleeping hours and excess weight in commercial drivers. Occup Med (Lond). 2015;65(9):725731.

97. McHill AW, Wright KP Jr. Role of sleep and circadian disruption on energy expenditure and in metabolic predisposition to human obesity and metabolic disease. Obes Rev. 2017;18(Suppl 1):15-24.

98. Gu F, Han J, Laden F, et al. Total and cause-specific mortality of us nurses working rotating night shifts. Am J Prev Med. 2015;48(3):241-252.

99. Drake CL, Roehrs T, Richardson G, et al. Shift work sleep disorder: prevalence and consequences beyond that of symptomatic day workers. Sleep. 2004;27(8):1453-1462.

100. Jennings JR, Muldoon MF, Hall M, et al. Self-reported sleep quality is associated with the metabolic syndrome. Sleep. 2007;30(2):2190-223.

101. Jay SM, Gander PH, Eng A, et al. New Zealanders working nonstandard hours also have greater exposure to other workplace hazards. Chronobiol Int. 2017;34(4):519-526. 